\title{
ABRASIVE BLASTING TECHNOLOGY FOR DECONTAMINATION OF THE INNER SURFACE OF STEAM GENERATOR TUBES
}

\author{
GYE-NAM KIM*, MIN-WOO LEE, HYE-MIN PARK, WANG-KYU CHOI, and KUNE-WOO LEE \\ Korea Atomic Energy Research Institute \\ 1045 Daedeokdaero, Yuseong-gu, Daejeon, Republic of Korea 305-353 \\ ${ }^{*}$ Corresponding author. E-mail : kimsum@kaeri.re.kr
}

Received December 03, 2010

Accepted for Publication April 11, 2011

The inner surfaces of bundled inconel tubes from steam generators in South Korean nuclear power plants are contaminated with cobalt and abrasive blasting equipment has been developed to efficiently remove the cobalt. The principal parameters related to the efficient removal using this equipment are the type of abrasive, the distance from the nozzle, and the blasting time. Preliminary tests were performed using oxidized inconel samples which enabled the simulation of cobalt removal from the radioactive inconel samples. The oxygen in the oxidized samples and the cobalt in the radioactive inconel were removed more effectively using the blasting distance, blasting time, and a silicon carbide abrasive. Using the developed abrasive blasting equipment, the optimum decontamination conditions for radioactive inconel samples were blasting for more than 6 minutes using silicon carbides under 5 atmospheric pressures.

KEYWORDS : Abrasive Blasting, Decontamination, Cobalt, Steam Generator, Inconel Tube

\section{INTRODUCTION}

Retired steam generators contaminated with nuclides during nuclear power plant operation are being accumulated quickly in the present conditions of the South Korean nuclear power plants. Until now, retired steam generators have been stored in the radioactive waste storage facilities in South Korean nuclear power plants. However, because the retired steam generators have a large volume, it is becoming necessary to reduce their volume through decontamination. Vascular bundle tubes made from inconel alloys constitute the largest part of the retired steam generators and the inner surfaces of these tubes are contaminated with cobalt, chromium and the other nuclides. Thus, waste reduction can be realized through the decontamination of the inner surface of the vascular bundle tubes of the retired steam generators.

Figure 1 shows the Kori- 1 steam generator from the Kori nuclear power plant in South Korea. It consists of 3,388 sets of long, slim inconel tubes. The specifications of the bundled inconel tubes in Kori- 1 are shown in Table 1. As can be seen from specifications, Kori- 1 requires much volume and it is necessary to develop an efficient method to decontaminate the inner surfaces of these vascular bundle tubes. The abrasive blasting technology was selected as the optimum technology for separating the nuclides from the inner surfaces of the retired steam generators because it can effectively remove the contaminants that are adhered to the inner surfaces of long, slim inconel tubes.

Ductile metal erosion has been studied using both macroscopic hardened steel spheres [1] and microscopic

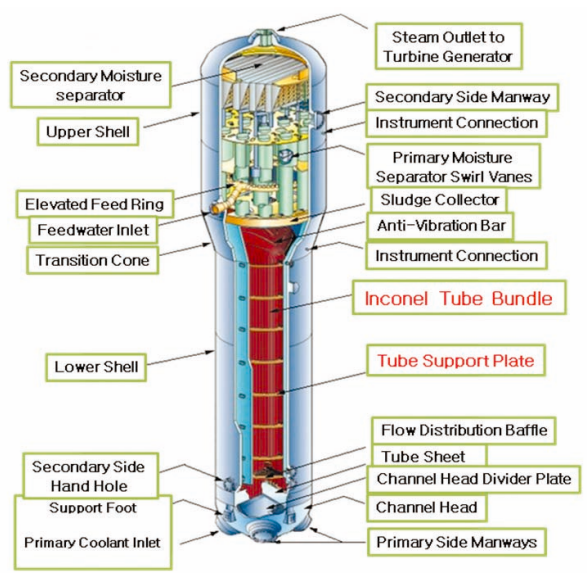

Fig. 1. The Retired Kori- 1 Steam Generator 
KIM et al., Abrasive Blasting Technology for Decontamination of the Inner Surface of Steam Generator Tubes

Table 1. Specifications of the Bundled Inconel Tubes from the Retired Kori- 1 Steam Generator

\begin{tabular}{c|c|c|c|c|c|c|c|c}
\hline Specification & $\begin{array}{c}\text { Total } \\
\text { Length } \\
(\mathrm{m})\end{array}$ & $\begin{array}{c}\text { Tube } \\
\text { Number } \\
(\mathrm{set})\end{array}$ & $\begin{array}{c}\text { Tube } \\
\text { Diameter } \\
(\mathrm{cm})\end{array}$ & $\begin{array}{c}\text { Tube } \\
\text { Thickness } \\
(\mathrm{cm})\end{array}$ & $\begin{array}{c}\text { Tube } \\
\text { Height } \\
(\mathrm{m})\end{array}$ & $\begin{array}{c}\text { Tube } \\
\text { Material } \\
(\mathrm{MA})\end{array}$ & $\begin{array}{c}\text { Min. } \\
\text { Radius } \\
(\mathrm{cm})\end{array}$ & $\begin{array}{c}\text { Max. } \\
\text { Radius } \\
(\mathrm{cm})\end{array}$ \\
\hline Value & 20.6 & 3,388 & 2.2 & 0.127 & 10.6 & 600 & 5.6 & 152 \\
\hline
\end{tabular}

particles [2]. When a particle arrives at the target surface at a certain velocity, it induces local material deformation; when its energy is higher than the fracture threshold of the material, the surface cracks and the initial parts of the target material are removed [3, 4].

Abrasive blasting is a technology that is being increasingly researched for the realization of threedimensional micro decontamination in brittle materials such as glass and silicon. This etching process is based on the eroding properties of $\mathrm{Al}_{2} \mathrm{O}_{3}$ sharp particles projected at high speeds against a target substrate. The origin of high- speed etching is the mechanical removal of matter through crack generation on the target surface [5, 6]. This technique was recently introduced for the microfabrication of small microsystems, such as cantilever accelerometer beams [7, 8]. Powder blasting has been proposed as a new, simple, very fast mechanical etching method for the fabrication of microsystems in brittle materials [9]. In an effort to improve the accuracy of the process, smaller particles with abrasion-resistant photosensitive polymers, such as polyurethane flexopolymers, have been proposed [10-12]. Also, high-resolution electroplated masks have been used [13] and resulting from its intrinsic simplicity and economic feasibility, this technique has a large application potential, even for high resolution patterning [14]. Studsvik Nuclear AB (Sweden) used a dry tube blasting method for the decontamination of heat exchangers for the first time in 1999. The heat exchangers had alpha and beta/gamma contamination inside the tube and the dry tube blasting equipment considerably reduced the production of secondary waste [15].

Abrasive blasting equipment was manufactured to detach the cobalt from the inner surface of steam generator tubes. The principal parameters for the efficient removal of the cobalt using the abrasive blasting equipment are the type of abrasive, the distance from the nozzle, and the blasting time. The optimum parameter conditions to obtain maximum removal efficiency were investigated through abrasive blasting experiments using new, oxidized, and radioactive inconel samples.

\section{EXPERIMENTAL}

\subsection{Equipment Manufacturing}

To decontaminate the inner surfaces of long, slim inconel tubes in the retired steam generators, KAERI designed the abrasive blasting equipment. The designed abrasive blasting equipment consists of a nozzle, protection room, cyclone, cyclone pan, dust collector, abrasive storage tank, and air compressor as shown in the 2D diagram presented in Figure 2. The inner surface of a contaminated inconel tube can be decontaminated using the abrasive particles that are released from the nozzle. The abrasive particles impinge on the back wall in the protection room, fall to the floor, and are then collected into the storage tank using a cyclone fan. Meanwhile, the radioactive dust separated from the tube's inner surface is collected using the dust collector. The air compressor supplies the high pressure to the nozzle. Figure 3 shows the manufactured abrasive blasting equipment.

\subsection{Abrasive Blasting Experiment with non- Radioactive Inconel Samples}

A schematic diagram of the abrasive blasting technology is shown in Figure 4. The erosion rate (Q) of the tube by the abrasive blasting can be described using equation [4]:

$$
Q=C \frac{\rho_{t} E^{5 / 4}}{H^{17 / 12} K_{t}} \rho_{P}^{1 / 6} r_{P}^{1 / 2} v_{P}^{7 / 3}
$$

where $\mathrm{E}$ is Young's modulus; $\mathrm{H}$ and $\mathrm{K}$ are the indentation hardness and fracture toughness of the tube, respectively; $\mathrm{v}, \mathrm{r}$, and $\rho$ are the abrasive velocity, abrasive radius, and abrasive density, respectively; and $\mathrm{t}$ and $\mathrm{p}$ are tube and particle, respectively.

Alumina \#80 and silicon carbide \#80 were used as the candidate particles for the abrasive blasting experiment. The new and oxidized inconel tubes were used as simulated samples for the experiments. The oxygen in the inconel tubes is a surrogate for the nuclides adhered to the tubes in the retired steam generators. The oxidation was performed with EDTA at $270{ }^{\circ} \mathrm{C}$ in an autoclave for 72 hours. The erosion rate of the inner surfaces of the inconel tubes was calculated by measuring the inconel tube weight before and after the abrasive blasting. The optimum decontamination conditions were verified by varying the distances from the nozzle and the blasting times.

Meanwhile, the new and oxidized inconel tube samples were manufactured to be $3 \mathrm{~cm}$ long, due to the difficulties in manufacturing oxidized inconel samples in an autoclave. The $3 \mathrm{~cm}$ long inconel sample was inserted into a 6 long connecting tube for the abrasive blasting experiment and the connecting tube was joined between two stainless 


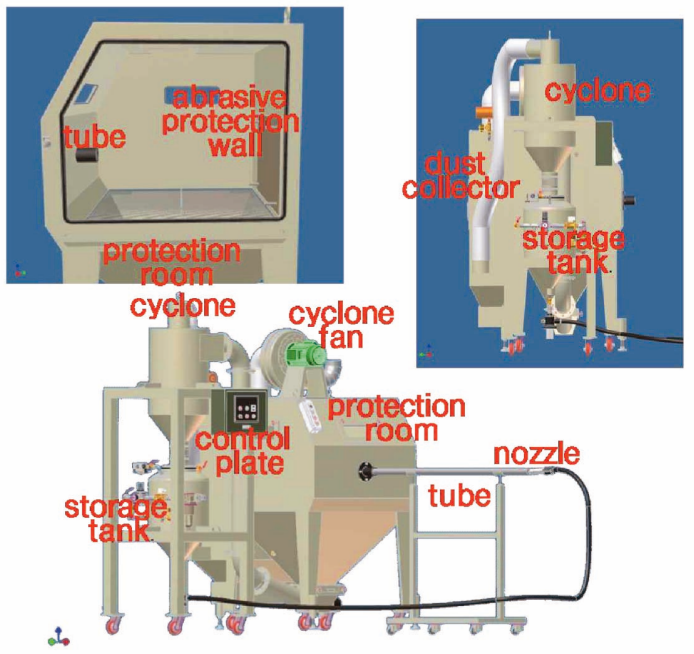

Fig. 2. 2D Image of the Designed Abrasive Blasting Equipment

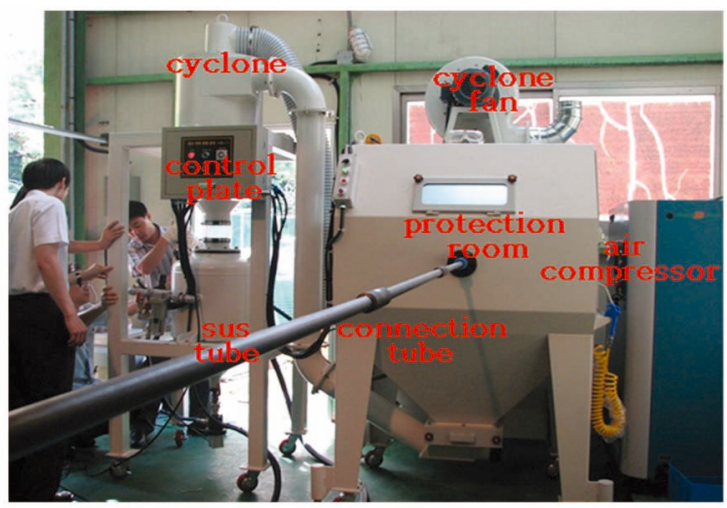

Fig. 3. The Manufactured Abrasive Blasting Equipment

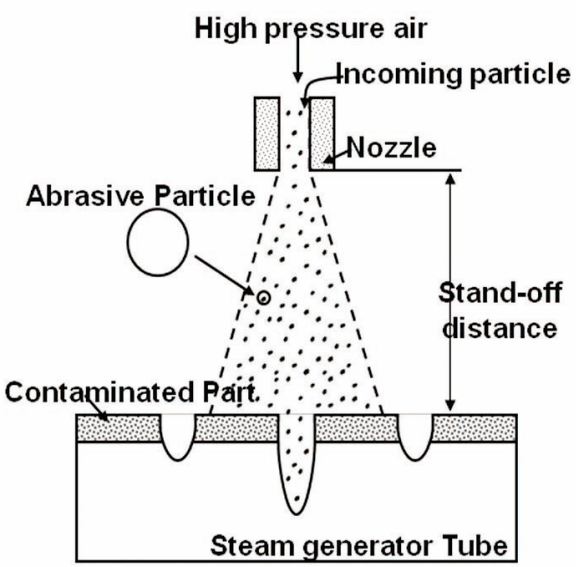

Fig. 4. Schematic Diagram of the Abrasive Blasting Equipment Setup for the Blasting Process steel tubes at $1 \mathrm{~m}, 2 \mathrm{~m}, 3 \mathrm{~m}$, and $4 \mathrm{~m}$, respectively (see Figures 3 and 5). The lengths of five pieces of stainless steel tubes were approximately $1 \mathrm{~m}$. The total length of the stainless steel tube including the connecting tubes was $5 \mathrm{~m}$. One end of the stainless steel was attached to the nozzle and the other end was located in the protection room for the experiment (see Figure 2). The tubes were disassembled after the experiment to measure the erosion weight that resulted from the dry abrasive blasting. The experiments were conducted for 3,6 , and 9 minutes for both the new and oxidized inconel tubes. Also, the air compressor uniformly supplied 5 atmospheric pressures to the nozzle.

\subsection{Abrasive Blasting Experiment with Radioactive Inconel Samples}

Based on the experimental results of the non-radioactive inconel samples, abrasive blasting experiments using radioactive inconel samples were performed. The radioactive inconel samples were extracted from retired steam generator and the main nuclide of the radioactive inconel samples was ${ }^{60} \mathrm{Co}$. The experiments with the radioactive inconel samples were performed in the Kori1 nuclear power plant. Radioactive inconel samples with a length of $3 \mathrm{~cm}$ were inserted into a connecting tube between two stainless steel tubes and positioned at $1 \mathrm{~m}, 3 \mathrm{~m}$, $5 \mathrm{~m}, 7 \mathrm{~m}$, and $9 \mathrm{~m}$.

The radioactivity of the radioactive inconel sample was measured using a multi-channel analyzer (MCA) with a standard tube of $50 \mathrm{cc}$, QCY48 (Amersham), manufactured by Korea Reach Institute Standards and Sciences (KRISS). The MCA is operated in the pulse height analyzer mode. A scintillation counter measured the pulse height distribution from the gamma ray source, and the amplitude of the incoming analog pulse was

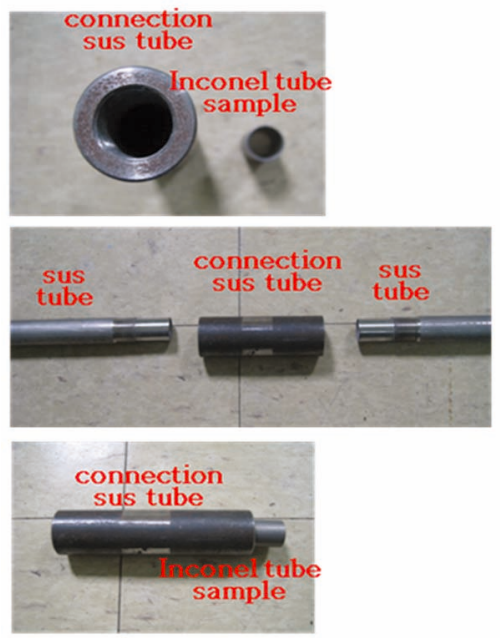

Fig. 5. Inconel Tube Sample Inserted Into a Connecting Tube, which was then Inserted between Two Stainless Steel Tubes 
digitized using an analog digital converter (ADC), with digital value being used as the address of the incremented memory location. Therefore, the screen display of the count number plotted against the channel number is a histogram of the count number plotted against the pulse height, i.e. a pulse height spectrum. The time required to measure the radioactivity of the inconel sample using the MCA was estimated to be between 1 hour and 8 hours depending on the radioactivity of the sample.

\section{RESULTS AND DISCUSSION}

\subsection{Abrasive Blasting Experiment with non- Radioactive Inconel Samples}

Figures 6 and 7 show the variation of the weight losses of the new and oxidized inconel samples, respectively, with the blasting distance using an alumina abrasive. The weight loss showed a maximum loss at a distance of $1 \mathrm{~m}$

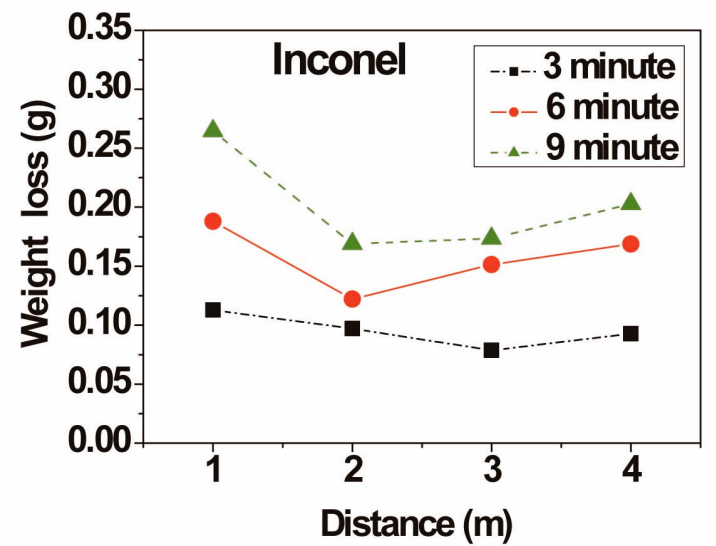

Fig. 6. Weight Loss of the New Inconel Tube with Variations in the Blasting Distance using an Alumina Abrasive

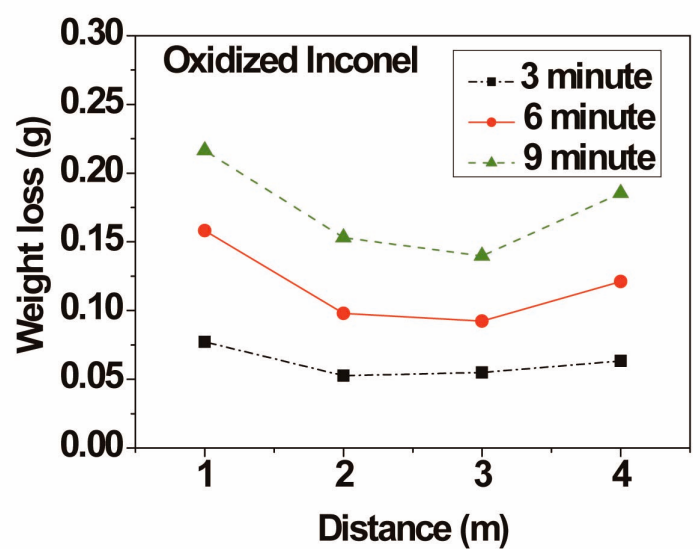

Fig. 7. Weight Loss of the Oxidized Inconel Tube with Variations in the Blasting Distance using an Alumina Abrasive and then decreased as the distance increased until approximately $3 \mathrm{~m}$, after which it began to increase again. The weight losses of the new inconel and oxidized inconel samples were largest at a distance of $1 \mathrm{~m}$ due to the closeness of the nozzle. At a blasting distance of $2 \mathrm{~m}$, the weight loss was lowest, with slight increases in the amount of weight loss from the inner surface of the oxidized inconel at nozzle distances of more than $2 \mathrm{~m}$. This is thought to be a result of the cyclone fan generating suction pressure in the protection room, changes in the vertical blasting, and the generation of an abrasive disturbance. Therefore, the effect of the blasting angle and abrasive velocity on the weight losses of the new and oxidized inconel samples was stronger than that of the blasting distance.

Figures 8 and 9 show that the weight loss of the new and oxidized inconel samples, respectively, varied with the blasting time. A longer blasting time resulted in a greater weight loss from the inner surfaces of the oxidized

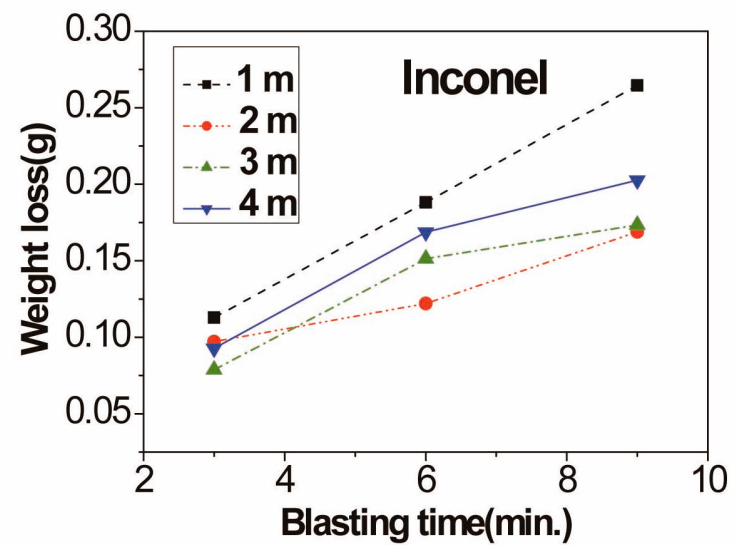

Fig. 8. Weight Loss of the New Inconel Tube with Variations in the Blasting Time using an Alumina Abrasive

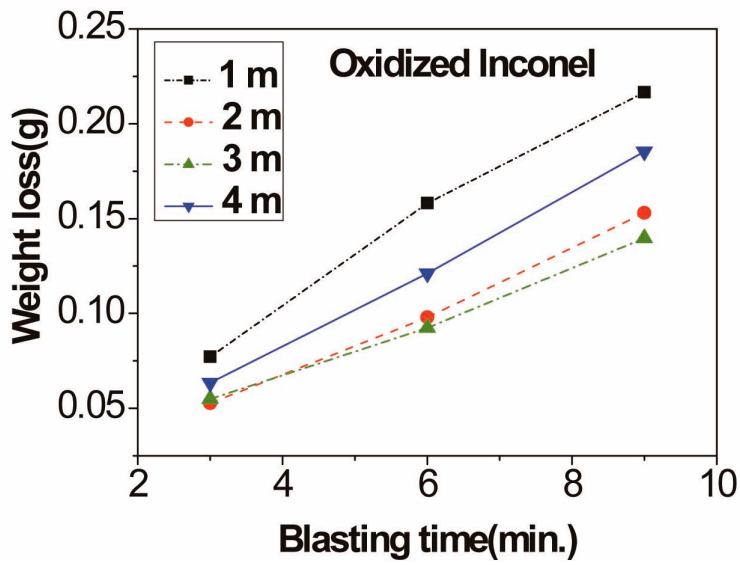

Fig. 9. Weight Loss of the Oxidized Inconel Tube with Variations in the Blasting Time using an Alumina Abrasive 
inconel: the weight loss increased 2.8 times using a threefold increase in the blasting time. Therefore, the blasting time should be controlled on the basis of the degree of contamination in the inner surface of the inconel tube. Meanwhile, comparing Figure 8 and 9, the average weight loss of the oxidized inconel tube was reduced by approximately $22.5 \%$ more than that of the new inconel tube due to the formation of an oxidation film.

Figures 10 and 11 show that the weight losses of the new and oxidized inconel samples, respectively, vary depending on the blasting distance when a silicon carbide abrasive is used. A longer blasting distance resulted in a larger amount of weight loss of the oxidized inconel. The weight losses of the new and oxidized inconel samples at $3 \mathrm{~m}$ and $4 \mathrm{~m}$ increased; the effects of the blasting angle and abrasive velocity on the weight losses of inconel samples were stronger than those of the blasting distance. However, the weight loss of the inconel sample at $1 \mathrm{~m}$

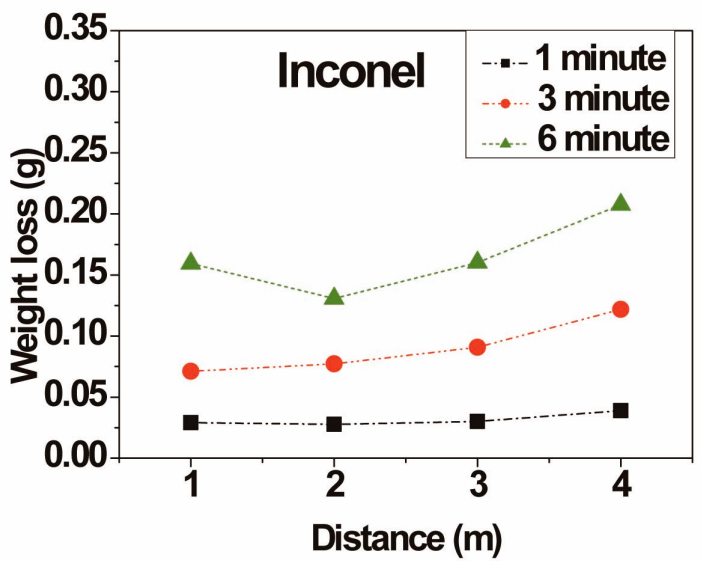

Fig. 10. Weight Loss of the New Inconel Tube with Variations in the Blasting Distance using a Silicon Carbide Abrasive

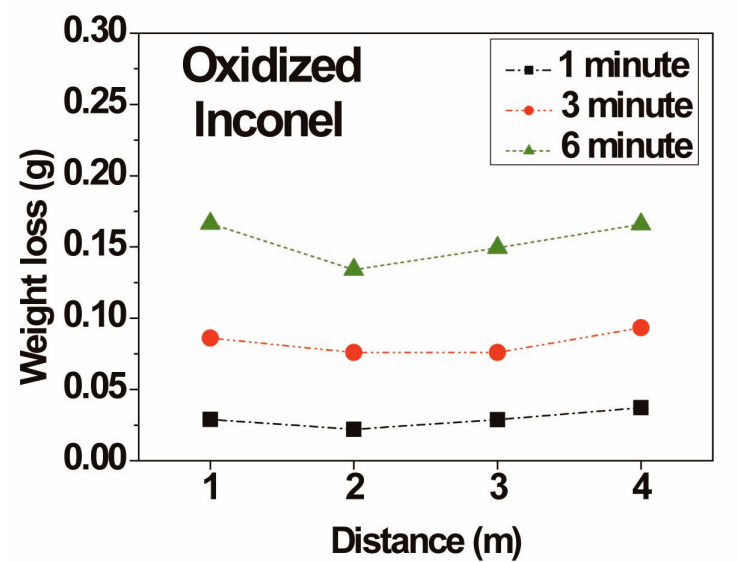

Fig. 11. Weight Loss of the Oxidized Inconel Tube with Variations in the Blasting Distance using a Silicon Carbide Abrasive increased due to the shorter nozzle distance and a larger blasting angle than at $2 \mathrm{~m}$. Also, the weight losses of the oxidized inconel samples were slightly reduced compared with those of the new inconel samples. It is considered that the oxidized inconel surface is harder than the new inconel surface. Comparing Figure 10 and 11, the average weight loss of the oxidized inconel was reduced by approximately $7.5 \%$ more than that of the new inconel due to the formation of an oxidation film.

Figures 12 and 13 show that the weight losses of the new and the oxidized inconel samples, respectively, vary with the blasting time when a silicon carbide abrasive is used. A longer blasting time results in a larger weight loss from the inner surfaces of the oxidized inconel. That is, the average weight loss increased by approximately 5.3 times with a sixfold increase in the blasting time. Therefore, the blasting time should be controlled based on the degree of contamination in the inconel tube.

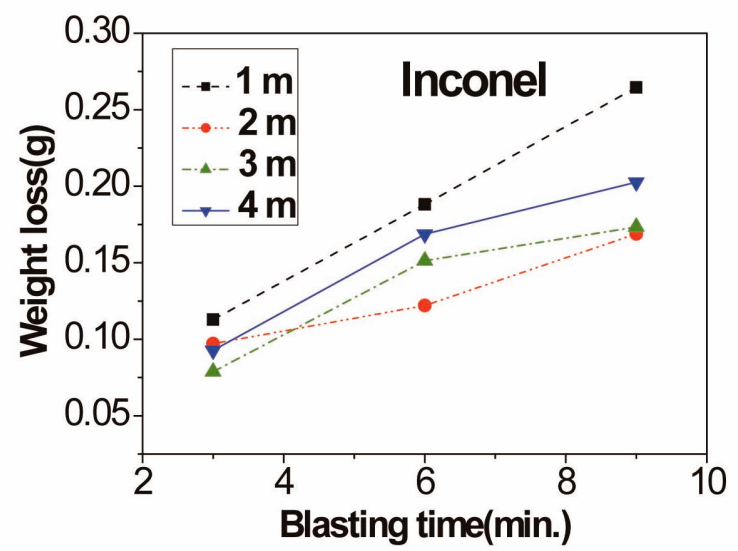

Fig. 12. Weight Loss of the New Inconel Tube with Variations in the Blasting Time using a Silicon Carbide Abrasive

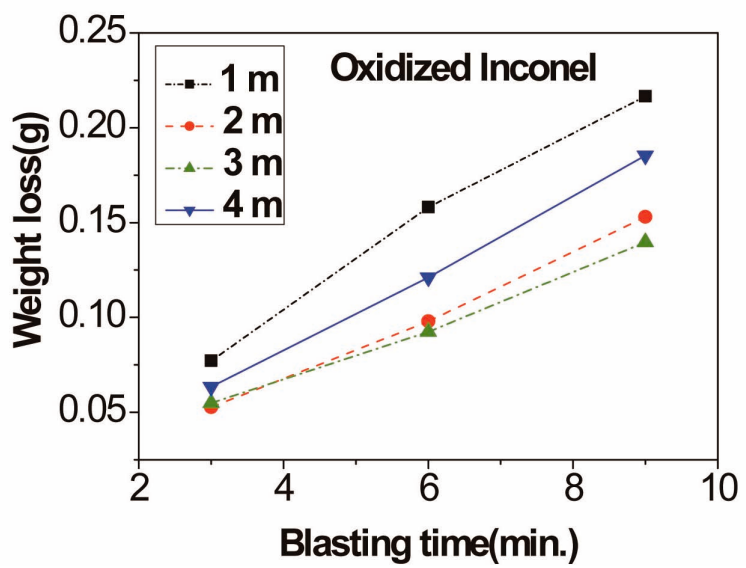

Fig. 13. Weight Loss of the Oxidized Inconel Tube with Variations in the Blasting Time using a Silicon Carbide Abrasive 


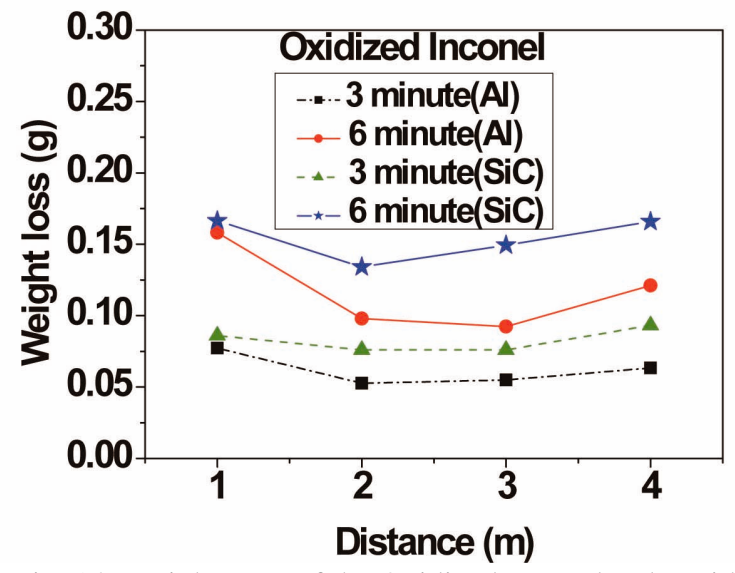

Fig. 14. Weight Loss of the Oxidized Inconel Tube with Variations in the Blasting Distance

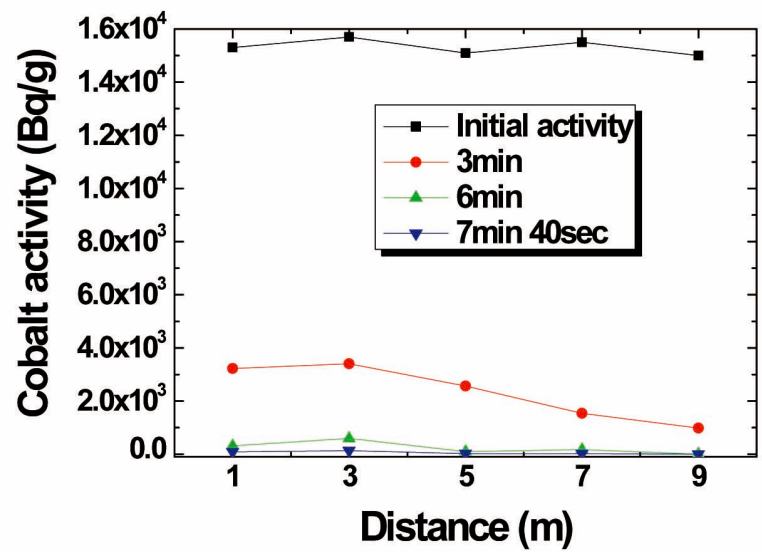

Fig. 15. Cobalt Activity with Variations in the Blasting Distance

Figure 14 shows that the weight loss of the oxidized inconel tube according to the blasting distance. The weight loss of the oxidized inconel tube using the silicon carbide abrasive increased by $32.3 \%$ compared with that of the oxidized inconel using the alumina abrasive, the reason of which is that bulk density and hardness of alumina \#80 are $1.6 \mathrm{~g} / \mathrm{cm}^{3}$ and $2.1 \mathrm{~kg} / \mathrm{mm}^{2}$, while those of silicon carbide $\# 80$ are $1.86 \mathrm{~g} / \mathrm{cm}^{3}$ and $2.8 \mathrm{~kg} / \mathrm{mm}^{2}$. Therefore, it was found that the silicon carbide abrasive was more effective than the alumina abrasive for the removal of contaminants from the inner surface of oxidized inconel samples.

\subsection{Abrasive Blasting Experiment with Radioactive Inconel Samples}

Figure 15 shows the dependence of the cobalt activity in the radioactive inconel samples on the blasting distance when silicon carbide is used. A longer blasting distance

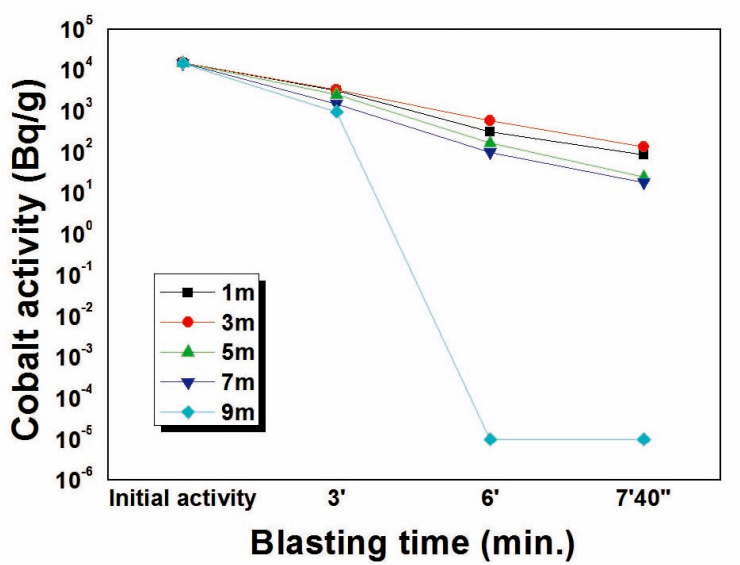

Fig. 16. Cobalt Activity with Variations in the Blasting time

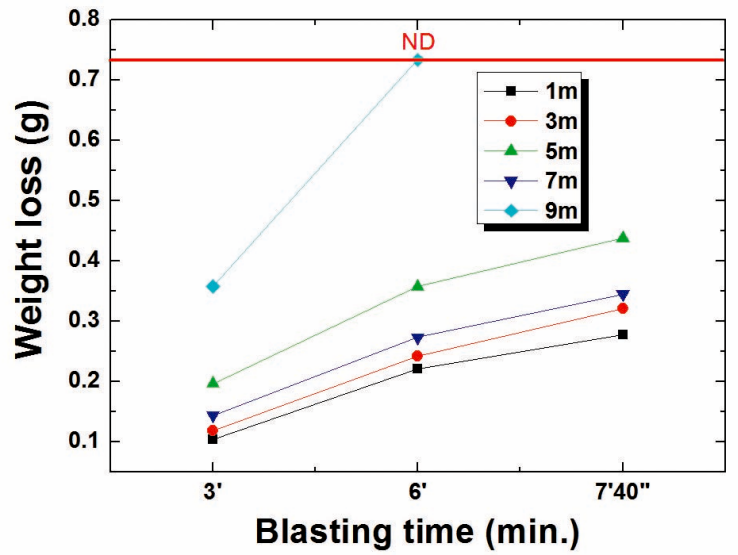

Fig. 17. Weight Loss with Variations in the Blasting Time

results in a drastic reduction in the cobalt activity of the radioactive inconel samples, which is consistent with the previous experiments. This results from an increase in the abrasive velocity at the end of the stainless tube due to the generation of suction pressure by the cyclone fan and a change in the vertical blasting angle. The blasting angle and abrasive velocity had stronger effects on the weight loss of the inconel sample than the blasting distance. However, the cobalt activity of the radioactive inconel sample at a $1 \mathrm{~m}$ distance decreased slightly more than that at $3 \mathrm{~m}$ position due to the shorter distance from the nozzle and the change in the blasting angle.

Figure 16 illustrates that the cobalt activity varies with the blasting time when the silicon carbide is used. A longer blasting time results in lower cobalt activity in the radioactive inconel sample consistent with the previous results. Figure 17 shows that the weight loss also varies with the blasting time: a longer blasting time results in a larger weight loss from the radioactive inconel sample. 


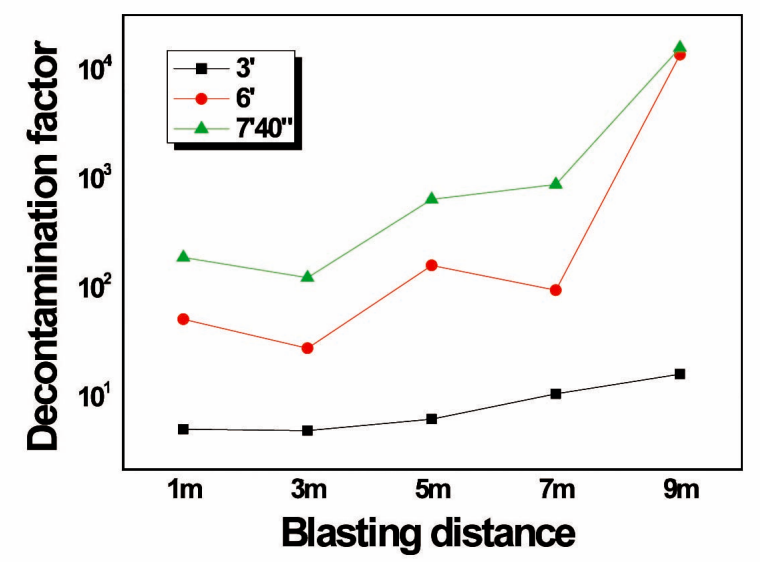

Fig. 18. The Decontamination Factor with Variations in the Blasting Distance

At a distance of $9 \mathrm{~m}$ from nozzle, the weight loss of the radioactive inconel sample after 6 minutes of blasting increased steeply. Figure 18 shows that the decontamination factor, which isthe ratio of the initial radioactivity to the final radioactivity resulting from abrasive blasting process, varies with the blasting distance for the silicon carbide abrasive. Furthermore, a longer blasting distance results in a larger decontamination factor. In particular, at $9 \mathrm{~m}$ from the nozzle, the decontamination factor of the radioactive inconel sample increased steeply. Meanwhile, the optimum decontamination conditions for the radioactive inconel samples using the developed abrasive blasting equipment are blasting time of more than 6 minutes using silicon carbides under 5 atmospheric pressures.

\section{CONCLUSIONS}

Abrasive blasting equipment was developed to decontaminate inconel tubes from the retired steam generators. A longer blasting distance resulted in a larger weight loss from the inner surface of oxidized inconel tubes, which is due to the generation of suction pressure in the protection room by the cyclone fan, a change in the blasting angle, and the generation of an abrasive disturbance. A longer blasting time also resulted in alarger weight loss. The weight loss was increased by approximately 2.8 times with a threefold increase in the blasting time. The average weight loss of the oxidized inconel tube was reduced by approximately $22.5 \%$ more than that of a new inconel tube under the same conditions due to the formation of an oxidation film in the oxidized samples. The weight loss of the inner surface of the oxidized inconel tubes was increased by $32.3 \%$ when a silicon carbide abrasive was used compared with the alumina abrasive. Meanwhile, a longer blasting distance resulted in a lower cobalt activity in the radioactive inconel samples. It is considered that the blasting angle and abrasive velocity were more effective than the blasting distance in increasing the weight loss of the inconel samples. A longer blasting time also resulted in a drastic reduction in the cobalt activity of the radioactive inconel sample. Accordingly, it is proposed that the optimum method to decontaminate the inner surface of a full-size radioactive inconel tube with a length of $20.6 \mathrm{~m}$ is to give a blast at both ends of it by one time, respectively, using a nozzle. Meanwhile, the optimum decontamination conditions for the radioactive inconel samples using the developed abrasive blasting equipment are blasting for more than 6 minutes using silicon carbides under 5 atmospheric pressures.

\section{ACKNOWLEDGEMENTS}

This work was supported by the Nuclear Research $\&$ Development Program of the South Korea Science and Engineering Foundation (KOSEF) with a grant funded by the Korean government (MEST).

\section{REFERENCES}

[ 1 ] I.M. Hutchings, N.H. Macmillan, D. G. Rickerby, "Further studies of the oblique impact of a hard sphere against a ductile solid," Int. J. Mech. Sci., 23 (1981).

[2] M. Dundar, O.T. Inal, J. Stringer, "The effect of particle size on the erosion of a ductile material at the low particle size limit," Wear, 233-235 (1999).

[ 3 ] G.P. Tilly, W. Sage. "The interaction of particle and material behavior in erosion processes," Wear, 16 (1970).

[4] M. Buijs, "Erosion of glass as modeled by indentation theory," J. Am. Ceram. Soc., 77 (1994).

[ 5 ] P.J. Slikkerveer, P.C.P. Bouten, F.H. int't Veld, H. Scholten, "Erosion and damage by sharp particles," Wear, 217,2 (1998).

[6] P.J. Slikkerveer, "Mechanical etching of glass by power blasting," PhD Thesis, Eindhoven University of Technology, (1999).

[7] E. Bolloy, S Thurre, E. Walckiers, A. Sayah, M.A.M. Gijs, "Powder blasting as a new technology for intertial sensor fabrication," Proc. 13 $3^{\text {th }}$ European conference on soild-state sensor, The Hague, The Netherlands, Sep. 12-15, 1999.

[ 8 ] E. Belloy, S. Thrre, E. Walckiers, A. Sayah, M. A. M. Gijs, "The introduction of powder blasting for sensors and microsystem applications," Sens. Actuators, A 84 (2000).

[9] T.S. Baller, G.G. P. van Gorkom, N. Nambert, E.A. Montie P.H.F. Trompenaars, S.T. de Zwart, "Construction and physical processings of Zeus panels," Philips J. Res., 50 (1996).

[10] J. Li, I.M. Hutchings, "Resistance of cast polyurethane elastomers to solid particle erosion," Wear, 135 (1990).

[11] P.J. Slikkerveer, M.H.A. van Dongen, F.J. Touwslager, "Erosion of elastomeric protective coating," Wear, 236 (1999).

[12] P.J. Slikkerveer, P.C.P. Bouten, F.C.M. de Haas, "High quality of brittle materials by powder blasting," Sensors Actuators ,85 (2000).

[13] H. Wensink, H.V. Jansen, J.W. Berenschot, M.C. 
Elwenspock, "Mask materials for powder blasting," $J$. Micromech. Microeng., 10 (2000).

[14] H. Wensink, J.W. Berenschot, H. V. Jansen, M.C. Elwenspoek, "High resolution powder blast micromachining," Proc. Int. Conf. Micro Electro mechanical Systems (MEMS-
2000), Miyazaki, Japan , Jan 23-27, 2000.

[15] G. Krause, "Concepts for treatment and recycling of Steam Generators and other big components from operation and decommissioning of nuclear facilities", International Nuclear Forum, 6TH - 8TH, Varna, Bulgaria, 2007 